\title{
The Effect of the Shared Savings Program on Medicare Part D Spending: Evidence from Rural and Underserved Areas
}

J Gen Intern Med 37(1):272-3

DOI: $10.1007 /$ s11606-020-06500-y

(C) Society of General Internal Medicine 2021

$\mathrm{T}$ he Medicare Shared Savings Program (SSP) encourages groups of providers to participate as accountable care organizations (ACOs). ACOs are incentivized to lower Medicare spending while improving quality of care for Medicare fee-for-service (FFS) beneficiaries. ACOs achieve these goals by sharing in a portion of savings (or needing to pay losses) based on attributed beneficiaries' spending relative to financial benchmarks and performance on quality measures.

The calculation of SSP incentives uses Medicare spending on Part A (institutional) and Part B (other medical services) but not Part D spending on prescription drugs. However, Medicare prescription drug spending through Part D is substantial, in absolute terms and as a proportion of total Medicare spending, and is growing rapidly. ${ }^{1}$ In hypothesis, ACOs might increase prescription drug spending directly through efforts to improve performance such as chronic disease control. Alternatively, ACOs may indirectly reduce prescribing as collateral effort to reduce Part A and B spending. Thus, the net impact is unclear. Examining changes in Part D spending may reveal that overall Medicare savings attributable to SSP are smaller or larger than previously described. Previous research has found limited effects of ACOs on prescription drug use, adherence, and expenditures, but has not examined Part D spending in the SSP. ${ }^{2,3}$

A recent study found that ACOs participating in the ACO Investment Model (AIM) successfully reduced Medicare Parts A and B spending. ${ }^{4}$ AIM targeted small ACOs in more rural and underserved areas, which were not representative of the 517 ACOs currently participating in SSP. ${ }^{5}$ Nonetheless, the AIM evaluation provides an opportunity to examine changes in Part D spending among a group of SSP ACOs that were successful in reducing Medicare spending while maintaining quality. Below, we provide recent estimates of the effects of the SSP on Medicare prescription drug spending among 41 AIM ACOs.

Received September 17, 2020

Accepted December 17, 2020

Published online January 6, 2021

\section{METHODS}

We analyzed Medicare Parts A and B claims using Medicare claims and enrollment data and Part D spending using the Cost \& Use files from the Chronic Condition Warehouse for 20132018. The Part D spending did not include rebates or discounts.

Our analysis focused on Medicare FFS beneficiaries with full Part D coverage who were eligible for attribution to SSP ACOs. The intervention group consisted of beneficiaries attributed to the 41 AIM ACOs which participated in AIM in all three performance years. The comparison group included beneficiaries not attributed to a Medicare ACO who shared a market with ACO beneficiaries. Our outcome of interest was perbeneficiary-per-month (PBPM) Medicare Part D expenditures.

We used a difference-in-difference framework with weighting and regression adjustment, following Trombley et al. (2019), to estimate changes in Part D spending for intervention beneficiaries from the baseline to performance period, relative to concurrent changes among comparison beneficiaries. ${ }^{5}$ To account for changes in provider composition, we estimated effects for each performance year separately using the most appropriate baseline.

\section{RESULTS}

The analysis included 32,824,382 beneficiary-years, with ACO beneficiaries accounting for $10 \%$ of annual samples on average. ACO and comparison beneficiaries were similar in the baseline and small differences were stable from the baseline to the performance period. Table 1 shows regressionadjusted average Part D spending for ACO and comparison beneficiaries for the baseline and performance years (PYs). In PYs 1 and 3, AIM reduced prescription drug spending by $\$ 3.11(-1.54 \% ; p<0.01)$ and $-\$ 5.44(-2.68 \% ; p<0.01)$ PBPM, respectively. The change in PY2 was not statistically significant $(-\$ 1.63$ PBPM $[-0.81 \%] ; p=0.37)$.

\section{DISCUSSION}

AIM was a voluntary model, which may raise the question of whether estimates were susceptible to changes in provider or beneficiary composition over time. AIM ACOs demonstrated in the first performance year that they were able to reduce Part D expenditures. Although the baseline may have become a less appropriate comparator over time, subsequent years 
Table 1 Medicare Part D Spending Difference-In-Difference Estimates over PY1-PY3 with Unique Comparison Groups for Each PY

\begin{tabular}{|c|c|c|c|c|c|c|c|}
\hline & \multicolumn{2}{|l|}{ AIM ACOs } & \multicolumn{2}{|l|}{ Comparison } & \multirow{2}{*}{$\begin{array}{l}\text { Differential change for ACOs vs. } \\
\text { control group, } \$(95 \% \text { CI) }\end{array}$} & \multirow{2}{*}{$\begin{array}{l}p \\
\text { value }\end{array}$} & \multirow{2}{*}{$\begin{array}{l}\text { Percent change } \\
\text { from baseline, } \\
\%(95 \% \mathrm{CI})^{\mathrm{a}}\end{array}$} \\
\hline & $\begin{array}{l}\text { Performance, } \\
\$\end{array}$ & $\begin{array}{l}\text { Baseline, } \\
\$\end{array}$ & $\begin{array}{l}\text { Performance, } \\
\$\end{array}$ & $\begin{array}{l}\text { Baseline, } \\
\$\end{array}$ & & & \\
\hline $\begin{array}{l}\text { PY1 } \\
\text { (2016) }\end{array}$ & 198.60 & 210.53 & 204.26 & 213.09 & \multirow{3}{*}{$\begin{array}{l}-3.11 \\
(-5.42 \text { to }-0.80) \\
-1.63 \\
(-5.19 \text { to } 1.94) \\
-5.44 \\
(-10.19 \text { to }-0.69)\end{array}$} & 0.01 & \multirow{3}{*}{$\begin{array}{l}-1.54 \% \\
(-2.68 \text { to }-0.3 \%) \\
-0.81 \% \\
(-2.56 \text { to } 0.95 \%) \\
-2.68 \% \\
(-5.02 \text { to }-0.34 \%)\end{array}$} \\
\hline $\begin{array}{l}\text { PY2 } \\
\text { (2017) }\end{array}$ & 200.66 & 221.48 & 203.05 & 222.24 & & 0.37 & \\
\hline $\begin{array}{l}\text { PY3 } \\
(2018)\end{array}$ & 197.40 & 218.15 & 200.98 & 216.29 & & 0.02 & \\
\hline
\end{tabular}

Abbreviations: $A C O$, accountable care organization; AIM, ACO Investment Model; PY, performance year; $C I$, confidence interval

Estimates of changes in Medicare Part D spending were calculated by comparing that of AIM ACO-assigned beneficiaries to non-ACO fee-for-service (FFS) beneficiaries residing in the AIM ACOs' markets. All beneficiaries were required to have full Part D coverage. Estimates above are in perbeneficiary-per-month (PBPM) terms. Performance Years 1-3 are 2016-2018, respectively. The baseline period spanned 2013-2015. We created performance year-specific comparison groups and baselines to ensure the validity of each year's estimates. Estimates were adjusted for sex, racelethnicity, age, whether the beneficiary originally qualified for Medicare due to an end-stage renal disease diagnosis, whether the beneficiary originally qualified for Medicare due to disability, dual Medicare/Medicaid eligibility status, whether the beneficiary was a resident of long-term institutional facility, hierarchical condition category score, indicators of conditions from the Chronic Condition Warehouse, death, months eligible for FFS Medicare, the number of concurrent chronic conditions, rurality as measured by Rural-Urban Commuting Area (RUCA) designations, indicators for Primary and Mental Health Professional Shortage Areas (HPSA), market fixed effects, and market-specific time trends. Stata (StataCorp, LLC) Version 16.0, was used to conduct analyses, and statistical significance was characterized as a p value lower than 0.05 for two-sided tests. Estimates in all 3 years passed the parallel trends assumption needed to support the validity of the difference-in-differences approach. While the data do not contain information on direct and indirect remuneration (DIR; e.g., rebates), we believe this does not pose a concern to the validity of our estimates, as our difference-in-difference design should mitigate the effects of DIR, assuming that AIM and comparison beneficiaries were not differentially affected ${ }^{a}$ Percent changes from the baseline were calculated by dividing the differential changes for ACOs versus comparison group by the baseline values of Part D spending for ACO beneficiaries during the baseline period net of the change in total Medicare spending of non-ACO FFS beneficiaries between baseline and performance years in ACO markets

confirm that, at minimum, AIM did not result in increased prescription drug spending. Given the conceptual rationalbe for this possibility discussed above, this finding should be of particular interest to CMS. Our findings indicate that Medicare savings attributed to AIM were not overstated due to increased Part D spending, which in turn suggests that the current design of SSP does not result in hidden costs to Medicare, at least in rural areas.

Acknowledgments: Analyses and access to Medicare claims and enrollment data in the Chronic Conditions Warehouse were funded by Centers for Medicaid and Medicare Services contract HHSM50020140026I Task Order HHSM500T0004. Preparation of this manuscript was supported by Abt Associates internal funds. We gratefully acknowledge the helpful commentary from attendees of Abt's Work-in-Progress Seminar.

Chao Zhou, $P h D^{1}$

Lauren M. Scarpati, $P h D^{1}$

Matthew J. Trombley, $P h D^{1}$

Betty Fout, $P h D^{1}$

${ }^{1}$ Abt Associates Inc., Rockville, MD, USA
Corresponding Author: Chao Zhou, PhD; Abt Associates Inc., Rockville, MD, USA (e-mail: Chao_Zhou@abtassoc.com).

\section{REFERENCES}

1. Kaiser Family Foundation. 10 Essential Facts About Medicare and Prescription Drug Spending. 29 Jan 2019. https://www.kff.org/infographic/10-essential-facts-about-medicare-and-prescription-drug-spending/. Accessed 27 May 2020.

2. Zhang Y, Caines KJ, Powers CA. Evaluating the effects of pioneer accountable care organizations on Medicare Part D drug spending and utilization. Medical care. 2017 May 1;55(5):470-5.

3. McWilliams JM, Najafzadeh M, Shrank WH, Polinski JM. Association of changes in medication use and adherence with accountable care organization exposure in patients with cardiovascular disease or diabetes. JAMA cardiology. 2017 Sep 1;2(9):1019-23.

4. Trombley MJ, Fout B, Brodsky S, McWilliams JM, Nyweide DJ, Morefield B. Early Effects of an Accountable Care Organization Model for Underserved Areas. New England Journal of Medicine. 2019 Aug 8;381(6):543-51.

5. Centers for Medicare and Medicaid Services. Shared Savings Program Fast Facts - As of January 1, 2020. https://www.cms.gov/files/document/ 2020-shared-savings-program-fast-facts.pdf. Accessed 14 Jul 2020.

Publisher's Note: Springer Nature remains neutral with regard to jurisdictional claims in published maps and institutional affiliations. 